\title{
Editorial for the Indigenous use of Information and Communication Technologies Section
}

\author{
Peter Radoll \\ University of Newcastle \\ Peter.Radoll@newcastle.edu.au

\section{John Campbell} \\ University of Canberra \\ john.campbell@canberra.edu.au
}

The rapid rise in the use of information and communication technologies (ICTs) by Indigenous people and communities is an intriguing development with implications for Indigenous cultures. ICTs have a critical role to play in supporting Indigenous selfdetermination, strengthening Indigenous identity, and providing a strong Indigenous political voice. ICTs also have potential to address Indigenous disadvantage through connecting business and government to Indigenous communities. However, potential negatives also exist. ICT use can give rise to negative consequences by diminishing cultural meanings and exposing individuals to new kinds of online-related risks.

The initial idea for this special section arose during a panel discussion on Indigenous Peoples and Information Systems at the 2014 Australasian Conference on Information Systems. From that discussion it emerged that the use of ICTs had become an everyday, typical activity, utilised by Indigenous people and communities for a range of purposes. In so doing, ICTs provide Indigenous people with ways to circumvent limitations imposed by governments and mass media. Widespread ICT usage has allowed Indigenous peoples not only to disseminate their views, but also to build grassroots alliances with similarly minded groups. ICT has the ability to bring together Indigenous groups globally in an online community that constitutes an informal nation, which exists outside of government regulation and controls, and builds solidarity.

For this special section of AJIS, we encouraged submissions that focused on aspects of Indigenous use of ICTs in workplaces, educational settings, community, and specific personal and cultural applications. In so doing we wanted to examine important properties of information systems use unique to Indigenous peoples, and to highlight the ways new technologies enable creative engagement and a means for Indigenous people to represent themselves with less regulatory interference. In this special issue we present three papers that address a variety of issues related to ICTs and Indigenous peoples.

The first paper represents a social media study in which Carson, Farrelly and Borthwick examine how Aboriginal people utilise and interact on social media, and how these technologies can assist with suicide prevention strategies. They found that Aboriginal people are engaging with Facebook to both seek and offer help for issues relating to suicide and selfharm. These findings have significant implications for the design and implementation of effective suicide prevention programs for Indigenous Australians. The second paper by Ashraf, Grunfeld, and Quazi examines how the use of ICTs affects the livelihoods of an Indigenous community in Bangladesh. The findings demonstrate that ICTs have a positive impact by improving the livelihoods of Indigenous individuals and communities. The third paper examines attitudes to e-government adoption in the Kurdistan Region of Iraq and thus provides insight into the factors affecting the adoption of e-government by an indigenous ethnic minority in an emerging democratic state. Ahmed and Campbell distinguish between informational and transactional e-government services and their findings have implications for the implementation of e-government services for indigenous peoples of the Middle East.

Research on the use of ICTs by Indigenous peoples is growing in prominence, yet the area overall is still very under theorised and much more research is required to better understand both the challenges and the opportunities that ICTs brings to the Indigenous space. 
Copyright: (C) 2015 Radoll \& Campbell. This is an open-access article distributed under the terms of the Creative Commons Attribution-NonCommercial 3.0 Australia License, which permits non-commercial use, distribution, and reproduction in any medium, provided the original author and AJ IS are credited.

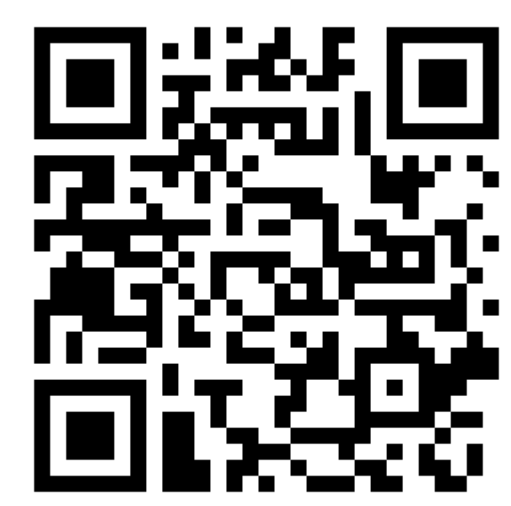

